\title{
ISSN No. 2631-2743
}

\section{KAIR@́S}

Iliana López Ruiz

ilopez@uotavalo.edu.ec

Universidad de Otavalo Facultad de Derecho (Otavalo - Ecuador)

ORCID: 0000-0001-9737-7469

\section{Luis Fernando Haro Haro}

fer_haroluis@hotmail.com

Universidad de Otavalo Facultad de Derecho (Otavalo - Ecuador)

ORCID: 0000-0001-6516-2260
NEOCONSTITUCIONALISMO EN EL ECUADOR, UNA MIRADA DESDE LA ARGUMENTACIÓN MORAL Y LA PONDERACIÓN

NEOCONSTITUTIONALISM IN ECUADOR, A VIEW FROM MORAL ARGUMENTATION AND WEIGHTING

\section{DOI:}

https://doi.org/10.37135/kai.03.07.07
Recibido: 13/04/21

Aceptado: 30/06/21 


\section{Resumen}

El Derecho ha transitado por etapas que marcaron su evolución hasta el Neoconstitucionalismo actual. Se define esta teoría desde una óptica teórica, ideológica y metodológica. El objetivo es ilustrar si dentro de este modelo, la ponderación y la argumentación moral, son los métodos que pueden garantizar una adecuada aplicación de la norma constitucional en casos donde exista colisión de derechos o principios. Se pudo concluir que, el Neoconstitucionalismo implica supremacía constitucional, integra los principios como elemento esencial para la protección de derechos y otorga protagonismo al juez como intérprete de la ley a través de la Ponderación, permitiéndole dilucidar y aplicar las normas y principios a casos concretos y así resolver de forma pormenorizada.

\section{Palabras clave}

Neoconstitucionalismo, moral, derecho, argumentación, ponderación.

\section{Abstract}

The Law has gone through stages that marked its evolution until the current Neoconstitutionalism. This theory is defined from a Theoretical, Ideological and Methodological point of view. The objective is to illustrate whether within this model, pondering and moral argumentation are the methods that can guarantee an adequate application of the constitutional norm in cases where there is a collision of rights or principles. It was possible to conclude that Neoconstitutionalism implies constitutional supremacy, integrates the principles as an essential element for the protection of rights and gives prominence to the judge as interpreter of the law through Weighting, allowing him to elucidate and apply the norms and principles to specific cases and so solve in detail.

\section{Keywords}

Neoconstitutionalism, moral, law, argumentation, weighing.

\section{NEOCONSTITUCIONALISMO EN EL ECUADOR, UNA MIRADA DESDE LA ARGUMENTACIÓN MORAL Y LA PONDERACIÓN}

NEOCONSTITUTIONALISM IN ECUADOR, A VIEW FROM MORAL ARGUMENTATION AND WEIGHTING 


\section{Introducción}

El Ecuador, materializando un nuevo modelo de sistema jurídico que busca superar al antiguo Estado legal, ha dado el paso a la configuración de un Estado constitucional, donde los derechos y la idea de justicia son el eje central. Este constitucionalismo integra nuevas concepciones ideológicas y filosóficas como lo sería, por ejemplo, la consecución de un modelo de vida denominado "el buen vivir", una nueva forma de concebir o entender la materialización de los derechos.

Se afirma de este modo la implementación de un neoconstitucionalismo en el Ecuador, entendido como una reformulación de la idea de Estado, en el sentido de la incorporación en su ordenamiento jurídico de un amplio contenido de principios y valores que dan a los jueces la posibilidad de realizar ejercicios interpretativos frente a un extenso catálogo de derechos. La figura del juez cobra fuerza, como desarrollador de jurisprudencia a través de la cual se materializa, optimiza y viabiliza, el contenido de la propia norma. Es así como el neoconstitucionalismo viene a poner fin a antiguos dogmas iuspositivistas y reivindica de alguna manera la prevalencia de los derechos constitucionales por encima incluso de la propia ley. Para autores como Carbonell (2010), el neoconstitucionalismo es una teoría que:

(...) plantea una nueva concepción del Estado constitucional, en constituciones garantistas caracterizadas por amplios catálogos de derechos fundamentales, lo que viene a suponer un marco de relaciones entre el Estado y los ciudadanos muy renovado, sobre todo por la profundidad y grado de detalle de los postulados constitucionales que recogen tales derechos. (p.24)

Visto desde este ámbito, este modelo institucionaliza la protección de los derechos constitucionales a través de la propia Constitución. Téngase en consideración que otorga relevancia a los principios sobre las reglas, y favorece lo que se puede llamar una adecuación de la administración de justicia a las circunstancias del caso concreto. En este sentido cobran un rol protagónico los métodos de interpretación constitucional, como lo son la ponderación o la argumentación moral. A esto se suma la relevancia de la figura del juez y la importancia de la especialidad de en materia constitucional.

En este marco, el presente trabajo tiene como objetivo realizar un breve esbozo sobre la teoría neoconstitucionalista, abordando algunas de sus definiciones teóricas. Autores como Comanducci, lo circunscribe desde el punto de vista teórico, ideológico y metodológico, como una vía para comprender el alcance de algunos de sus principales elementos. Igualmente, es necesario analizar si los métodos de interpretación de la 
ponderación y la argumentación moral específicamente responden adecuadamente a los fines planteados por la teoría. Entre estos, la protección de derechos en primer lugar y cómo se manifiestan estos métodos a través del rol del juez constitucional específicamente.

Es así como se realiza un análisis con un enfoque cualitativo desde el punto de vista jurídico, para describir cómo se ha desarrollado la teoría neoconstitucionalista en el sistema jurídico constitucional ecuatoriano, y al mismo tiempo estudiar en qué medida la ponderación y a la argumentación moral son métodos de interpretación adecuados para su desarrollo desde una perspectiva normativa, siendo el juez el eje central para la consecución de este fin.

De igual manera es preciso establecer la necesidad de que los operadores de justicia posean un nivel de especialidad en materia constitucional, para que los mismos puedan ser capaces de aplicar los métodos de interpretación constitucional que se describen, de una manera correcta y debidamente motivada. Estos elementos armonizados permitirán establecer la validez de estos métodos de solución de conflictos en materia de derechos y principios a través de sus alcances al momento de su aplicación.

\section{Neoconstitucionalismo, una mirada desde la historia}

Estados de derecho, Estados constitucionales, son sin dudas legados de variados y convulsos procesos transformadores que marcaron notoriamente a la humanidad, hasta llegar hablar de neoconstitucionalismo, una nueva forma de concebir la estructura estatal, con límites propugnados precisamente por el garantismo de derechos y la supremacía constitucional.

Es por ello por lo que debemos definir el tema más importante y que sin dudas, tiene tantas definiciones como defensores y detractores. Estamos hablando del neoconstitucionalismo. El término fue utilizado por primera vez en el año 1997, a la luz del XVIII Congreso de Filosofía Jurídica y Social celebrado en Argentina, por la Doctora Susana Pozzolo, quien en una disertación sobre el tema sacó a la palestra el análisis del Neoconstitucionalismo, que hasta hoy muchos doctrinarios pueden decir que es una ideología, como por ejemplo Robert Alexy o Dworkin, entendiendo que pueden subsistir elementos como el derecho y la moral al amparo de la propia norma constitucional. También puede verse como una visión nueva del Estado de derecho donde el fin mayor es la consagración de la supremacía de la Constitución sobre el resto de las normas. Una visión donde las reglas o preceptos jurídicos son vistos como expresiones positivizadas de la ley y los principios como la más genuina expresión constitucional. Para Pozzolo (2016) ofrece "otra oportunidad 
precisamente desde la idea que la elección de interpretar las normas como reglas o como principios cambia el equilibrio entre los poderes estatales y sus competencias" (pp. 142).

En este sentido, la Constitución se erige como la máxima expresión de consagración de derechos, donde la base fundamental se encuentra en el reconocimiento de los principios como base para la interpretación de las normas. Otras ideas indican que es una corriente filosófica o una doctrina según la cual los principios constitucionales se tienen que interpretar haciendo referencia a su contenido moral o a las doctrinas morales que ellos transmiten. Según esta posición de la autora Pozzolo (2016) citando a Nino (1985) ha indicado que, "la teoría positivista que separa claramente entre derecho y moral no funciona, precisamente porque para dar sentido a los principios no se puede ignorar su contenido moral" (p. 144).

Como ya se ha indicado, el paso al neoconstitucionalismo no fue un proceso rápido. Todo lo contrario, los cambios se gestaron de manera gradual y paulatina. A entender de la autora Pozzolo (2016), fue un proceso cíclico en la consumación real de los derechos, el cual implicó el desarrollo, por parte de la jurisprudencia, de una creciente actitud interpretativa e intervencionista, a través de la cual se presenta como un importante actor en el nuevo contexto democrático" (p.143).

La relevancia de esto radica precisamente en que la Constitución, como Ley Suprema, ya no solo tenía la responsabilidad de regular en materia de derechos, sino que iba aún más lejos, su contenido era una expresión democrática y garantista de estos derechos, incluso más allá del texto mismo, la hermenéutica constitucional y los principios implícitos en ella tomaban casi la misma importancia que su contenido en sí. Esto sería el punto de encuentro entre el derecho positivizado en norma y los mandatos de optimización que para lograr la protección de los derechos constitucionales se hacían imprescindibles.

En el caso de Ecuador, por ejemplo, asimilar normativamente las primicias que este modelo implica ha sido un proceso que se ha desarrollado poco a poco, y que se consagra en gran medida con la promulgación de la Constitución de 2008.

En la misma se amplía el catálogo de derechos y se introducen categorías novedosas como el "sumak kawsay", que en lenguaje kichwa significa o hace referencia a una vida ideal, de realización en armonía con el universo, la naturaleza y el ser humano. Así lo indica la ley fundamental al señalar que se reconoce "una nueva forma de convivencia ciudadana, en diversidad y armonía con la naturaleza, para alcanzar el buen vivir, el sumak kawsay" 
(p.8). En la norma constitucional de Montecristi en el artículo 14 se indica que:

Art. 14.- Se reconoce el derecho de la población a vivir en un ambiente sano y ecológicamente equilibrado, que garantice la sostenibilidad y el buen vivir, sumak kawsay. (Constitución del Ecuador, 2008)

Como bien revela la norma constitucional se reconoce una nueva forma de vida, que sin dudas tiene incidencia directa en la formación de un nuevo estado constitucional de derechos y justicia, donde la diversidad y la pluriculturalidad se expresen incluso a través del sistema jurídico. En este sentido, a pesar de que el modelo neoconstitucionalista tuvo mucho que ver en la mayor parte de estos cambios, no se puede decir que sea un modelo consagrado y consolidado de manera completa en el Ecuador, sino que ha ido transformando el sistema jurídico de manera gradual, autores como Ávila (2012) lo definen acertadamente de la siguiente manera:

Se trata, pues, de construir un estado y un derecho diferentes. Los grandes trazos y las pistas para esa construcción los encontramos en el artículo primero de la Constitución, que son un llamado para hacer un salto paradigmático del estado tradicional y neoliberal a un estado realizador del buen vivir. (p.80)

Es evidente que esta nueva forma de constitucionalismo o modelo neoconstitucionalista ha llegado a revolucionar las anteriores concepciones positivistas y tradicionalistas del derecho, es el caso de Ecuador y algunos otros países de la región como Bolivia, por ejemplo. La idea central de este modelo es hacer de los derechos fundamentales el eje central de los sistemas jurídicos, así mismo lograr distanciarse del formalismo y positivismo jurídico, dando especial relevancia a los principios y valores, para respaldar nuevos conceptos de derechos sociales y culturales, la pluriculturalidad y la interculturalidad. Es así como autores de la región como el propio Ramiro Ávila (2012) han entendido que "la propuesta constitucional de estos países andinos supera al neoconstitucionalismo como nos ha llegado desde el viejo continente."

\section{El Neoconstitucionalismo teórico, ideológico y metodológico}

No es un secreto que la propia teoría del derecho ha tenido que adaptar sus postulados para explicar los cambios que ha significado la evolución de un Estado legislativo a un Estado constitucional, para finalmente hablar de Estado neoconstitucionalista. Carbonell (2003), por ejemplo, señala que "con el término neoconstitucionalismo se hace referencia también a una determinada teoría del derecho que propugnado en el pasado reciente por 
esos cambios y/o que da cuenta de ellos, normalmente en términos bastante positivos o incluso elogiosos" (p.10). Ahora, si realmente constituye una teoría o no y las bondades que aporta, es un tema bastante polémico desde el punto de vista doctrinal.

La idea sería lograr identificar ciertos elementos que lo componen, para esto autores como Comanducci (2002) han establecido las diferencias entre estos dos modelos alegando que existen diferencias entre el Constitucionalismo y el Neoconstitucionalismo, respecto a este último indica lo siguiente:

El neoconstitucionalismo, como teoría del derecho, aspira a describir los logros de la constitucionalización, es decir, de ese proceso que ha comportado una modificación de los grandes sistemas jurídicos contemporáneos respecto a los existentes antes del despliegue integral del proceso mismo. El modelo de sistema jurídico que emerge de la reconstrucción del neoconstitucionalismo está caracterizado, además que por una constitución "invasora", por la positivización de un catálogo de derechos fundamentales, por la omnipresencia en la constitución de principios y reglas, y por algunas peculiaridades de la interpretación y de la aplicación de las normas constitucionales respecto a la interpretación y a la aplicación de la ley. Como teoría, el neoconstitucionalismo representa por tanto una alternativa respecto a la teoría iuspositivista tradicional (prr. 28).

En este orden de ideas se evidencia que el neoconstitucionalismo nace como una expresión jurídica y filosófica, es decir, va más allá de ser una simple teoría del derecho. Se identificaba con una ideología en defensa de los derechos fundamentales y dirigida a la limitación del poder. Para autores como Vigo (2015) "el Neoconstitucionalismo se hace cargo de los "casos difíciles" respecto de los cuales corresponde apartarse de las respuestas contenidas en las normas porque resultan claramente irracionales o absurdas axiológicamente" (p.860). Es así como esta corriente avizora grandes avances en lo referente a la hermenéutica constitucional. Sin embargo, los criterios contrapuestos indican que solo se traduce en una falta de seguridad jurídica, que dejará al ordenamiento jurídico positivo desplazado ante la discrecionalidad y elementos subjetivos de este modelo.

Autores como Comanducci hablan continuamente de la existencia de diferentes tipos de neoconstitucionalismo. Se hace referencia, por ejemplo, al Neoconstitucionalismo Teórico, donde encontramos doctrinarios como Ferrajoli y Zagrebelsky. Este último, por ejemplo, refiriéndose a la nueva visión del derecho dentro del neoconstitucionalismo ha indicado que “...el derecho se transforma en una realidad "dúctil” en manos de los jueces, abandonando así las rigideces legalistas. Se adopta por parte de los jueces una actitud antiformalista, que orientan su actuación en los principios "pro homine" y "favor libertatis" (p.286). Es por ello que se realizará un acercamiento a estas clasificaciones dadas por el autor Paolo Comanducci sobre el neoconstitucionalismo. Refiriéndose a la 
clasificación teórica de este modelo Comanducci (2002) establece que el mismo conserva cierta relación la conexión circunstancial entre derecho y moral; al afirmar que:

Como teoría, el neoconstitucionalismo representa por tanto una alternativa respecto a la teoría iuspositivista tradicional: las transformaciones sufridas por el objeto de investigación hacen que ésta no refleje más la situación real de los sistemas jurídicos contemporáneos. En particular, el estatalismo, el legicentrismo y el formalismo interpretativo, tres de las características destacadas del iuspositivismo teórico de matriz decimonónica, hoy no parecen sostenibles. (prr.28)

Es así como, si analizamos esta teoría se puede evidenciar que es la máxima expresión de la constitucionalización del ordenamiento jurídico positivo, asume y juega el rol que necesariamente debe tener el texto constitucional. Es sin dudas una transformación a través de la cual la interpretación constitucional, se manifiesta excepcionalmente como consecuencia de un proceso de constitucionalización del derecho.

Se habla igualmente del Neoconstitucionalismo ideológico, que a decir del mismo Comanducci (2002) "no se limita por tanto a describir los logros del proceso de constitucionalización, sino que los valora positivamente y propugna su defensa y ampliación. En particular, subraya la importancia de los mecanismos institucionales de tutela de los derechos fundamentales" (prr.33). Es decir, aquí ya se puede materializar cuestiones como la técnica de "ponderación" para resolver conflictos o colisiones entre principios, lo que sin dudas desencadena una serie de elementos basados en la interpretación "moral" de la Ley fundamental, una manera distinta y novedosa de aplicar la justicia constitucional, aunque para muchos autores como el ya citado Comanducci es una consecuencia que se puede tornar peligrosa al indicar que no brinda seguridad jurídica al momento de decidir sobre un asunto determinado.

A grandes rasgos trata de vincular el poder legislativo y el poder judicial bajo la premisa de la protección y garantismo de los derechos, entendiéndose que elementos como moral y derecho pueden coexistir dentro de los ordenamientos jurídicos con el objetivo de alcanzar la justicia y el bien común. Este elemento es el más discutido, pues esta idea se asocia para algunos directamente con elementos que denotan falta de certeza y seguridad jurídica.

En resumen, según el Neoconstitucionalismo Ideológico, Comanducci (2016) expone que "se debe obediencia al derecho solo si tiene un determinado contenido, es decir, si se conforma a una Constitución que tiene a su vez un determinado contenido: una Constitución formada por un conjunto de principios, valores y derechos fundamentales 
que constituyen la positivización de la moral crítica” (p.48). Según se puede observar la razón para obedecer y acatar las normas según esta teoría va a recaer en la moral, que nace directamente de ella, para luego materializarse en la norma constitucional y viceversa; en cualquier caso, derecho y moral serán elementos codependientes el uno del otro.

Por último, se debe analizar el llamado Neoconstitucionalismo metodológico, tesis seguida por autores como Robert Alexy y Dworkin, y que en esencia indica que los principios constitucionales son el nexo necesario entre el derecho materializado en norma, y la moral como trasfondo de cada una de las reglas que conforman el ordenamiento jurídico, así lo describe Comanducci (2016) cuando expone que:

El neoconstitucionalismo metodológico sostiene, por el contrario - al menos respecto a situaciones de derecho constitucionalizado, donde los principios constitucionales y los derechos fundamentales constituirían un puente entre derecho y moral - la tesis de la conexión necesaria, identificativa y/o justificativa, entre derecho y moral. (p. 53)

Aquí la gran dicotomía radica en establecer si realmente las decisiones de los jueces o sus juicios de valor deben ir basadas en normas morales, para el autor Comanducci, el neoconstitucionalismo encubre una falsa promesa de derecho mejor o más justo, en el que el rol protagónico de los jueces es bastante discutido. Esto es una postura bastante radical por parte del autor italiano, pues evidentemente el papel del juez constitucional en este modelo responde a la necesidad de dar un paso hacia delante en materia de protección de derechos y buscar la vía para que estos postulados se puedan aplican a un sin número de problemas y de casos en concreto que evidentemente no pudo ni podrá prever el legislador.

Lo cierto es que a pesar de las detracciones que lo rodean, esta concepción ideológica nos transporta a los postulados iusnaturalistas que van más allá de los referentes teóricos del propio constitucionalismo, donde la interpretación juega un papel fundamental a través de sus diferentes métodos como la ponderación y la argumentación moral, dado precisamente su amplio contenido de principios, comobien indica Bernal(2009) comoidea esencial en su narrativa "los derechos fundamentales constitucionales tienen estructura de principios jurídicos y se aplican judicialmente mediante la ponderación."(p.516)

Por todo lo anterior es necesario realizar un análisis crítico de algunos elementos que establece el autor italiano Comanducci en sus postulados, pues si se analizan estas clasificaciones parecería que la Constitución puede ser clasificada según su función o 
aplicación dentro del sistema jurídico. Al mismo tiempo tampoco establece una afiliación a una de estas clasificaciones o modelos, sino que brinda un acercamiento desde la teoría y la jurisprudencia, lo que no es errado siempre y cuando el análisis verse sobre la base de la interpretación constitucional en el contexto del caso concreto y no sobre la aplicación subjetiva de métodos de hermenéutica constitucional en abstracto.

\section{El neoconstitucionalismo frente al modelo principialista de derecho}

No se puede hablar de neoconstitucionalismo sin hablar al unísono de principios, y es que estos elementos complementan todo un andamiaje jurídico que coadyuva dentro de la práctica judicial, en lo que a protección de derechos se refiere. Ferrajoli (2011), por ejemplo, prefiere hablar del «Constitucionalismo iusnaturalista al definir que está caracterizado por "por la configuración de los derechos fundamentales como valores o principios morales estructuralmente distintos de las reglas, en cuanto dotados de una normatividad más débil, confiada no a la subsunción sino, más bien, a la ponderación legislativa y judicial" (p.21). Igualmente, el autor hace referencia al Constitucionalismo iuspositivista estableciendo que esta teoría se basa en lo siguiente:

Se caracteriza, en cambio, por una normatividad fuerte, de tipo regulativo, es decir, por la tesis de que la mayor parte de (si no todos) los principios constitucionales y, en particular, los derechos fundamentales, se comportan como reglas, pues implican la existencia o imponen la introducción de las reglas consistentes en las prohibiciones de lesión u obligaciones de prestación, que son sus respectivas garantías. (p. 21)

Sin embargo, todas estas concepciones filosóficas han transitado por diversas etapas, mismas que evidencian su evolución desde el positivismo de Kelsen con sus posteriores moderaciones, o el propio concepto positivista desde la lógica analítica de Ferrajoli. Sin embargo lo cierto es que, lo que tienen estas teorías en común es precisamente que, "conciben gran parte de las normas constitucionales y, en particular, de los derechos fundamentales, como principios ético-políticos; y que adoptan una distinción cualitativa y estructuralmente fuerte de principios y reglas, los primeros objetos de argumentación y ponderación, las segundas objeto de aplicación en la forma de la subsunción" (Ferrajoli, 2011, p. 20).

Lo mismo sucede entonces cuando se habla de neoconstitucionalismo, es que se mezclan una serie de elementos teóricos que no se pueden desvincular, pues tiene definitivamente concepciones afines al iusnaturalismo y por qué no, también se puede decir que posee elementos positivistas. Como bien establece Ávila (2012) “(...) es un error considerar que el neoconstitucionalismo es único y homogéneo" (p. 5). Realmente la definición podría 
ser el menor de los conflictos, dado que en el momento actual cuando de argumentación jurídica se habla, es importante que los juristas tengan claro las diferencias entre los valores morales y postulados jurídicos. Si bien el ius naturalismo ha trabajado mucho el tema no es menos cierto que en los conflictos sociales actuales, es menester teorizar sobre la forma de encontrar criterios de corrección en cuestiones morales y jurídicas diversas.

Podríamos entonces, apostar por un orden jurídico coartado por juicios morales con pretensiones de objetividad y certeza, esto como máxima expresión de la supremacía del estado constitucional de derechos, sin que esto signifique asfixiar al sistema jurídico y judicial con una práctica netamente moralista y que, argumentativamente, esta presunta moral oficial sea la cuna de gestación de nuevos augurios creadores de derecho y de justicia. Esto es precisamente porque en ninguna circunstancia se comparte desde el punto de vista social y jurídico una idea única o una tesis objetiva que permita diferenciar los postulados jurídicos de lo que identificamos como moralmente procedente.

Ciertamente estos términos no se han logrado separar si de derecho se habla, y menos si es precisamente el momento exacto cuando entran en contradicción estos principios, autores como Moreso (2009) incluso afirman que:

Los conflictos entre principios que regulan derechos se manifiestan en los casos en que un individuo requiere, por razones conceptuales o empíricas, la no satisfacción del derecho de otro individuo. Se trata, pues, de discusiones que se dan entre diversas instancias del mismo derecho o entre instancias particulares de derechos diferentes entre dos o más titulares. (p. 324)

Es necesariamente obligatorio según este análisis encontrar un equilibrio que permita reconocer el trasfondo moral y principialista detrás de cada una de las reglas que legítimamente reconocemos, si se analiza que desde el punto de vista jurídico los principios se pueden aplicar dada su naturaleza de manera abierta y flexible a cada caso, mientras que las normas o reglas como se conoce en el lenguaje constitucional son más cerradas o poco adaptables en su aplicación. El neoconstitucionalismo podría ser la máxima expresión y respuesta a este tan debatido objetivismo moral, que, a nuestro modo de ver, mezcla lo que autores como Ferrajoli llamaba constitucionalismo ético y su idea de principialismo ponderativo.

La relación entonces entre derecho y moral cada vez parece ser más innegable. Por una parte, al exponer que es necesaria la apertura e incorporación de concepciones morales al trasfondo de los postulados jurídicos, y, por otra parte, una tesis que de hecho es bien discutida al momento de hablar de justicia, es precisamente hasta qué punto nuestras 
normas jurídicas son justas, es entonces cuando aparece la aplicación del modelo principialista como la salida idónea para poder definir un Estado Constitucional de Derechos. ¿Podríamos hablar entonces de un sistema jurídico justo solo basado en el contenido estricto de las normas? Para dar respuesta a esta interrogante es meritorio hacer referencia a la narrativa de autores como Ávila (2012) al establecer de manera enfática que "la lógica del derecho por principios ha contribuido a resolver estos problemas históricos. El principio desata las manos del juez y permite hacer justicia en el caso cuando la regla es injusta (p.9).

Ante esto es perentorio cuestionar algunos argumentos de la teoría positivista, los cuales emergen bajo la restricción y limitación de reglas jurídicas positivas, inflexibles y en algunos casos inaplicables a temáticas tan socialmente variables y controversiales como lo fue en su momento el matrimonio igualitario o el aborto, los derechos de los animales y de la naturaleza, estos por sólo mencionar unos pocos ejemplos. Visto desde esta óptica la respuesta parece clara, no se puede hablar de un sistema jurídico justo y podríamos ir más allá, válido y eficaz solo basado en la aplicación de reglas.

En este punto la concepción neoconstitucionalista se encuentra en otra dimensión, sobrepasa el discurso jurídico que tanto conocemos, pues muchos teorizantes plantearán que se trata de una desnaturalización del derecho en sí mismo, quedando sólo un argumento convincente de fundamentación moral objetiva. Ante esto creemos que no es descabellado pensar en un equilibrio entre estos conceptos, difícil claramente pero no imposible. Autores como Sanchís (2011) afirman que:

\footnotetext{
(...) la validez de la norma no depende de su contenido de justicia y, por tanto, que pueden existir normas válidas e injustas y que la sola justicia no convierte a una norma en jurídica, me parece compatible con los mayores excesos objetivistas y cognoscitivistas a propósito de la moral. Por ello, no veo ningún inconveniente en escindir el discurso práctico y mostrarse como un «iusnaturalista» partidario del objetivismo y del cognoscitivismo en materia moral y como un positivista en Derecho. (p.237)
}

Sin duda la práctica judicial ha demostrado que la validez de una norma a veces no va a ser condicionada por si su contenido es realmente justo o injusto. Robert Alexy (1994) como principal exponente de este criterio ha indicado que:

Hay otro elemento de conexión entre el derecho y la moral que parece separarse del positivismo ético y aproximarse más al iusnaturalismo. Se trata del llamado argumento de la injusticia, y que consiste en negar carácter jurídico a las normas no ya simplemente injustas, sino injustas de una manera insoportable, cuando se traspasa un determinado 
umbral de injusticia, las normas aisladas de un sistema jurídico pierden el carácter jurídico. (45)

De igual forma la idea de alcanzar un estado de justicia a través de las normas, no basta para convertir a una norma jurídica en válida, y esto no necesariamente desvirtúa los conceptos positivistas, pues la ley escrita en ocasiones tiene estos matices que se manifiestan a través de su validez y eficacia de aplicación. En tal caso lo que se debe valorar es que no se puede sacrificar la justicia en aras del cumplimiento de normas, que, si bien en algún momento abarcaron eficazmente el desarrollo social del individuo dentro de una colectividad, al transcurrir del tiempo estas propias reglas no consiguen ser lo suficientemente idóneas para resolver casos o situaciones específicas y novedosas que se gestan continuamente dentro de la sociedad actual.

Siguiendo este criterio se hace evidente que no es posible evadir el rol protagónico del modeloprincipialista dederechosyel papeldelosjueces en cuantoa Neoconstitucionalismo se refiere, sin que con eso se reste importancia a la seguridad jurídica que proveen las reglas. Sería más bien comprender que en ocasiones la flexibilidad que emana de los principios puede mostrar el camino para decisiones más justas. Téngase en observancia que a toda regla le subyacen principios y valores que el legislador trató de proteger mediante criterios normativos específicos, pues si bien es cierto que en ocasiones no basta solo leer una norma para poder establecer su carácter moral y determinar si la misma es justa o injusta, se debe realizar un análisis del caso concreto y frente a esto es de vital importancia de la valoración que le puedan llegar a dar el juez, que como se ha afirmado son un elemento muy importante dentro de la teoría del neoconstitucionalismo.

\section{Argumentación moral y ponderación en el neoconstitucionalismo ecuatoriano}

Cuando se habla del término argumentación jurídica, rápidamente los juristas aluden su significado al hecho de proporcionar, exponer razones o elementos de razonamiento, que permitan demostrar una tesis o persuadir al juez al momento de emitir un juicio de valor respecto a una situación específica sometida a su entendimiento. Dicho de esta forma parecería que los elementos donde se sustenta una adecuada argumentación deberían reducirse al resultado en base a reglas establecidas, es decir basado única y exclusivamente en lo dicho por la ley. Ante esto autores como Atienza (1998) al referirse a la argumentación jurídica han afirmado que: 
Parece simplemente descabellado pensar que la justificación jurídica sea independiente de la justificación moral, esto es, que no exista - en algún sentido - una conexión esencial entre la argumentación jurídica y la moral; y todavía más descabellado, que esa justificación consista exclusiva o fundamentalmente en una justificación de tipo lógico-deductivo. (p. 37)

Para doctrinarios como Robert Alexy (2008), que también comparten estos criterios, "se erige el derecho como una teoría de la argumentación práctica, donde considera a la argumentación jurídica, como un caso especial del discurso práctico general, situando este discurso como un discurso moral (p.530). Es decir, para el autor alemán las decisiones objetivas de los jueces tienen un alto componente moral, aún y cuando se fundamenten en reglas preexistentes tiene un trasfondo de valoración, donde se desentraña lo que realmente es correcto de lo incorrecto, lo justo y lo injusto, es decir lo que social y moralmente es procedente como conducta dentro de la sociedad.

Y es que no hay duda de que el componente moral dentro de la sociedad ha constituido un elemento trascendental cuando de derecho se trata, para Ávila (2012) "la moral podría ser considerada una fuente más del derecho, si consideramos que los derechos humanos son valores reconocidos y acordados universalmente. No cualquier valor tiene que ser considerado por el derecho sino aquellos que están constitucionalizados.” (p. 146).

Precisamente en este punto lo que es relevante si de argumentación moral se habla, es que en la nueva Constitución de Montecristi se proclaman principios de aplicación directa y eficaz de los derechos, así que según el artículo 11 del texto constitucional todos derechos y garantías establecidos en la Constitución y en los instrumentos internacionales de protección de derechos humanos serán de directa e inmediata aplicación. Es por lo que, la teoría de la argumentación jurídica en este sentido se ve obligada a reconocer sus propias limitaciones y debe explorar otros caminos acordes al nuevo modelo constitucionalista, con las particularidades de un razonamiento jurídico lógico ajustado en un contexto determinado.

Sobre la relación de los elementos morales y la argumentación jurídica autores como García Figueroa (2017) han establecido que "si el Derecho está vinculado a la moralidad argumentativamente, paralelamente, la moral también ha sido sometida a una perspectiva argumentativa que integra los distintos dominios de la razón práctica" (p. 305). Sin embargo, aun y cuando el neoconstitucionalismo da paso a estas prácticas argumentativas, es necesario precisamente atendiendo a la propia naturaleza del modelo que, para asegurar la protección de los derechos y un acercamiento a un concepto de justicia, se evidencie de alguna forma objetividad y racionalidad en los elementos 
argumentativos, pues sin ellos quedaría desvirtuada totalmente su aplicabilidad.

Otro elemento de gran trascendencia en la práctica judicial actual es la aplicación del método de la ponderación. Si definimos en que consiste la ponderación, se debe indicar en palabras simples que la ponderación es un método o técnica argumentativa, podría decirse también que es una herramienta interpretativa, además, desarrollada y defendida por Robert Alexy, la que tiene como objetivo esencial resolver conflictos entre derechos fundamentales y principios cuando estos entran en contradicción unos con otros. En palabras de Pozzolo (2016) "la ponderación se entiende como la forma adecuada para la aplicación de los principios, mientras la subsunción lo seria para las reglas. (p.145).

Lo anterior evidencia que la colisión o conflictos entre los derechos y los principios es inevitable, y lamentablemente el legislador está impedido de poder prever la totalidad de ellos en la norma escrita, la interpretación es la única salida que les queda a los jueces. Esta interpretación debe ser debidamente motivada bajo los parámetros descritos en la propia norma y así mismo la argumentación de cada fallo no debe apartarse de una base normativa coherente, es decir el juez debe evitar que la discrecionalidad que le brindan estos métodos de resolución de conflictos se sobrepase de los límites establecidos en la propia norma. Lograr sopesar un derecho sobre otro o principios y reglas lleva un complejo análisis y es precisamente de lo que se trata la ponderación.

Aunque parezca claro el panorama, este es un tema que en los últimos años ha generado mucha polémica. Cuando se producen conflictos entre derechos o principios, los mismos deben resolverse aplicando un test de proporcionalidad, o sea, aplicando el principio de proporcionalidad que, para Alexy, es el principio último del ordenamiento jurídico. Según el autor el principio se subdivide, a su vez, en tres subprincipios: el de idoneidad, el de necesidad y el de proporcionalidad en sentido estricto o ponderación.

En el caso de Ecuador la Ley Orgánica de Garantías Jurisdiccionales y Control Constitucional ha desarrollado la ponderación como un método de interpretación, regulado específicamente en su artículo 3 numeral 3 de la norma de referencia, que indica lo siguiente:

Art. 3.- Métodos y reglas de interpretación constitucional. - Las normas constitucionales se interpretarán en el sentido que más se ajuste a la Constitución en su integralidad, en caso de duda, se interpretará en el sentido que más favorezca a la plena vigencia de los derechos reconocidos en la Constitución y que mejor respete la voluntad del constituyente.

(...) 3.- Ponderación. - Se deberá establecer una relación de preferencia entre los principios y 
normas, condicionada a las circunstancias del caso concreto, para determinar la decisión adecuada. Cuanto mayor sea el grado de la no satisfacción o de afectación de un derecho o principio, tanto mayor tiene que ser la importancia de la satisfacción del otro. (Ley Orgánica de Garantías Jurisdiccionales y Control Constitucional, 2009)

Como lo indica la propia norma existen elementos decisorios al momento de aplicar este método de interpretación. Se entiende que cuando un principio entra en contradicción con otro o con una norma es fundamental poder establecer el grado de afectación de un derecho con respecto a otro. La propia Ley Orgánica de Garantías Jurisdiccionales y Control Constitucional en el mismo articulado hace referencia en su numeral 2 a que:

(...) 2.- Cuando existan contradicciones entre principios o normas, y no sea posible resolverlas a través de las reglas de solución de antinomias, se aplicará el principio de proporcionalidad. Para tal efecto, se verificará que la medida en cuestión proteja un fin constitucionalmente válido, que sea idónea, necesaria para garantizarlo, y que exista un debido equilibrio entre la protección y la restricción constitucional. (Ley Orgánica de Garantías Jurisdiccionales y Control Constitucional, 2009)

Aunando en este estudio la Corte Constitucional ecuatoriana no ha sido ajena a esta práctica de interpretación, así lo indica en su Sentencia No. 0002-09-SIC-CC del año 2009, dentro del caso 0003-09-IC cuando indica que:

Debemos tener presente que, en el mundo jurídico global cada vez, con más intensidad, se hace evidente la tesis de que los sistemas jurídicos modernos están compuestos de dos tipos básicos de normas: Las reglas y los principios. Estos dos tipos de normas se aplican por medio de dos procedimientos diversos: la subsunción y la ponderación. Mientras las reglas se aplican por medio de la subsunción, los principios se aplican mediante la ponderación. Por este motivo, la ponderación se ha convertido en un criterio metodológico básico para la aplicación jurídica, en especial para la aplicación jurídica de los derechos humanos. (Corte Constitucional del Ecuador, 2009, p. 8)

De esta manera se hace necesario también dar una mirada a los criterios contrapuestos a la aplicación de la ponderación. Una de las principales alegaciones que se contrapone al tema de aplicación de la ponderación tiene que ver específicamente con el elemento racional de este método, y es allí donde existen criterios que mencionan que la ponderación es irracional por un sin número de razones, una de las más importantes descritas en la obra denominada La Racionalidad de la Ponderación, del autor Bernal (2015), es la referida a la indeterminación al expresar lo siguiente:

Resulta imposible imaginar que exista un procedimiento objetivo para la aplicación de los principios jurídicos. La indeterminación normativa abre siempre la puerta a las apreciaciones subjetivas del juez. Estas aparecerán indefectiblemente tanto en la ponderación como en cualquier otro procedimiento alternativo. (p.411). 
De igual manera otros autores como Leisner (1997) sostienen a través de los años que es totalmente imposible de predecir los resultados de la ponderación, y que esto es un impedimento relevante a la seguridad jurídica, así mismo explica que:

La crítica final mantiene que la ponderación es irracional porque sería imposible predecir sus resultados. Todos los resultados de la ponderación serían particulares, dependerían de las circunstancias de cada caso y no de criterios generales. Por consiguiente, las decisiones judiciales que emergen de la ponderación conformarían una jurisprudencia ad hoc, que tendería a magnificar la justicia del caso concreto mientras, correlativamente, sacrificaría la certeza, la coherencia y la generalidad del derecho. (p. 171).

Sin embargo de ello, y de que las posturas tanto detractoras como defensoras de este método son diversas, lo que es evidente es que la ponderación, materializada a través de una adecuada argumentación y motivación por parte del juez, ha puesto fin a muchos conflictos jurídicos para los cuales la norma no parece tener una respuesta clara. Los jueces al valorar elementos de cada caso concreto deben ser capaz de establecer en qué medida ha sido afectado un derecho con respecto a otro, y a su vez estará en condiciones de balancear un principio sobre otro que se le contrapone. Según Portocarrero (2017) al referirse a la ponderación y su adaptación a los casos concretos indica que:

“(...) la ponderación se limita a poner en relación los argumentos en favor y en contra de la aplicación de los principios en conflicto al caso concreto, mientras que el contenido y valor material de dichos argumentos no son aportados por la estructura de la ponderación, sino que se derivan de las circunstancias fácticas y jurídicas de cada caso" (p.210)

En Ecuador, un ejemplo de ello fue el caso 11-18-CN resuelto por la Corte Constitucional, caso 11-18-CN referente al matrimonio igualitario. El caso fue elevado en una consulta de norma por el Tribunal de la Sala Penal de la Corte Superior de Justicia de Pichincha sobre la constitucionalidad y aplicación de la Opinión Consultiva OC24/17 de la Corte Interamericana de Derechos Humanos, que reconoce el matrimonio de parejas homosexuales, sobre la posible contradicción de la Opinión Consultiva con las normas internas, pues en su caso la Constitución y la ley limitaban el matrimonio como un derecho exclusivo para parejas heterosexuales; $y$, por otra parte, la Opinión Consultiva de la corte Interamericana reconocía el matrimonio como un derecho para parejas del mismo sexo.

Para resolverla problemática, la Corte realiza un ejercicio de interpretación y ponderación, recurriendo al principio de proporcionalidad previsto en la Ley Orgánica de Garantías Jurisdiccionales y Control Constitucional, concluyendo finalmente que sin duda la Opinión Consultiva OC24/17, de la Corte Interamericana de Derechos Humanos forma 
parte del bloque de constitucionalidad, y por ende reconoce derechos que no han sido expresamente previstos en la Constitución pero que deben ser protegidos en virtud del principio de la aplicación directa y eficaz de los derechos constitucionales.

En este orden de ideas, es realmente notorio el empoderamiento del rol de juez y de los principios dentro del modelo neoconstitucionalista, sin el que este tipo de fallos no serían posibles. Parecería que, como máxima expresión del Estado Constitucional de Derechos, la ponderación se alza como una manera ineludible de alcanzar la justicia, aún por encima de la propia norma. Ante este escenario subsisten los criterios que afirman que los valores morales y los principios no se reglamentan por sí mismos, para ellos la ponderación significaría que todas las decisiones en materia judicial quedarían sometidas al arbitrio o criterio personal de quien las emita. Según estos razonamientos el control a través de las normas quedaría totalmente desplazado por el subjetivismo y esto significaría que no se podría hablar de seguridad jurídica, en tanto la decisión de un caso emane del juicio de valor subjetivo del juez.

Hay que decir que, en ambos casos los elementos aportados son realmente válidos teniendo en cuenta que, si bien es a veces necesario en aras de un proceder más justo realizar valoraciones subjetivas de los casos, también una excesiva discrecionalidad puede tornarse contradictoria si no va acorde a elementos normativos preexistentes. Es este un tema bastante controversial a la luz de que, si los jueces pueden, y de hecho están en la facultad de ponderar principios y reglas, y cada regla se dice tiene implícito un principio, algunos se preguntan ¿por qué no ponderar reglas con reglas? Esto es un tema que preocupa a muchos doctrinarios pues para autores como García Amado (2019) en debate sostenido sobre el tema ha indicado que "la ponderación es un instrumento particularista del que los jueces hacen uso para poder actuar de la manera más beneficiosa para ellos" (min. 17:00 -18:00). La situación se complica un poco más si se analiza que ante este criterio García Amado, indica que todas las reglas serían derrotables por un principio y a su entender ya no se hablaría de normas, sino de criterios personales y subjetivos de los jueces en cada caso concreto.

Finalmente hay que indicar que un problema real al que se enfrenta la aplicación del método de la ponderación y la argumentación moral en el Ecuador es que en el ordenamiento jurídico constitucional ecuatoriano no se establece una jerarquización de los derechos, o sea la norma constitucional ubica a todos los derechos un nivel jerárquico igualitario, donde determinar el contenido esencial de los mismos también es complejo, por lo que, sin esta jerarquización de derechos y ante la ambigüedad para determinar el contenido esencial de estos derechos para el operador de justicia es difícil al momento de 
establecer que derecho finalmente se sopesa sobre otro.

Sería prudente entonces que la Corte Constitucional, a través de su jurisprudencia, desarrolle estándares claros para determinar el contenido esencial de los derechos, teniendo en consideración que la propia Corte Constitucional ha adelantado algunos elementos en su sentencia 012-09-SEP-CC, pero al final no ha sido contundente en la medida de la identificación de estos elementos esenciales, como lo es la naturaleza jurídica, la finalidad y ejercicio funcional de los derechos. Esto sin duda aportaría en gran medida n grado de objetividad al momento de aplicar la ponderación en la resolución de casos concretos.

\section{Conclusiones}

Una vez realizado este análisis sobre los términos de argumentación, ponderación, moral, derecho, se puede concluir que el neoconstitucionalismo trajo consigo cambios realmente sustanciales, pues no cabe duda de que posesionó al juez como máximo intérprete de la Ley Suprema, convirtiéndolo no solo en un intérprete de la ley, sino que, en algunos casos en creador de Derecho.

Sin embargo, es necesario que los jueces se especialicen en materia constitucional, pues si bien la ponderación y los ejercicios argumentativos de interpretación son la respuesta a muchos casos donde la ley carece de claridad en su aplicación, no se puede inobservar la gran responsabilidad que revierte esta discrecionalidad otorgada a la figura del juzgador. Por ende, deben ser conocedores de estos estándares interpretativos en materia constitucional a fin de garantizar la vigencia de un modelo de justicia coherente y concordante en las decisiones dentro de cada una de las instancias

Esto tendría su lógica en el hecho de que al ponderar se está privilegiando un derecho o principio sobre otro y se debe tener claro bajo qué parámetros específicos se realiza este balance. Es claro que por mucho que lo intente el legislador no podrá prever estos conflictos entre derechos, al menos no en todos los supuestos, lo que preocupa a muchos en este caso es los ilimitados niveles de discrecionalidad y de subjetividad que puede acarrear la ponderación. En la práctica se ha podido evidenciar que existen casos donde la norma realmente no está a la altura de las situaciones sometidas a su aplicación, donde el Derecho como ente regulador de la sociedad no ha logrado sentar bases que avancen al ritmo versátil de las circunstancias imperantes, para esto la ponderación sin dudas fue la mejor respuesta. 
Así mismo se concluye que el principal problema no radica en decir si los principios son la respuesta a través de la ponderación, o lo es la aplicabilidad de las reglas, por medio de la subsunción. En tal sentido el conflicto podría ser en cómo y cuándo determinar las condiciones en que un principio debe ser aplicado como consecuencia de una vulneración de derecho. Se debe valorar en qué medida se puede modular la discrecionalidad del juez al momento de ponderar; de tal forma que su arbitrio no solo contenga como sustento la aplicación de un principio que considera más justo sobre otro, sino que sus criterios resulten válidos desde el punto de vista normativo, bajo elementos objetivos y en ninguna circunstancia ponderar en abstracto.

La solución a esta problemática puede desarrollarse por la Corte Constitucional a través de la jurisprudencia, sentencias modulativas que desarrollen estándares claros de interpretación y argumentación que permitan establecer el contenido esencial y alcance de los derechos y de esta manera realizar un ejercicio de ponderación adecuado. Téngase en consideración que el tribunal acude a la ponderación precisamente por la ausencia de una regla que le brinde una salida al caso, sin embargo, una vez decidido el mismo a través de este método de interpretación ya va a existir una regla o precedente jurisprudencial que sirva para la resolución de casos análogos a este. Este es el principal mérito del modelo neoconstitucionalista, pues permite esta flexibilidad en materia constitucional para la valoración y protección de los derechos por encima de cualquier otra lógica aportada por la norma positiva escrita.

Indudablemente en el neoconstitucionalismo el camino inevitablemente ha llevado a que coexistan la ponderación y la subsunción, que siguiendo una lógica garantista de derechos se debe reconocer que el Derecho objetivo positivizado en reglas sin dudas ha presentado una ineludible ambivalencia, pues en muchos casos no aportan una respuesta apropiada, es ahí donde la justicia en diversas circunstancias sería imposible de alcanzar sin que exista cierta elasticidad al momento de decidir por parte de los jueces, esta flexibilidad sólo puede alcanzarse a través de estos métodos de interpretación.

Se puede decir entonces que la clave es realmente resolver cuándo se debe recurrir al método de la ponderación y la argumentación con elementos morales, la respuesta podría ser más simple de lo que se ha planteado, el momento justo para ponderar sería aquel donde la norma no es capaz de resolver o aportar elementos que lleven a un entendimiento sobre un caso concreto. Cuando la propia regla queda desarmada ante elementos fácticos de casos específicos sin que logre llenar o responder de manera acertada los vacíos que dieron lugar a la situación problemática. En estos casos hay que darse cuenta de que el derecho es más que un sistema de reglas, verlo de esta forma sería 
limitarlo a una racionalidad que no siempre puede traducirse en justicia. La ponderación puede ser y de hecho lo ha sido en muchos casos, el camino más corto para lograr los fines incluso propuestos por la propia norma con razones realmente plausibles, siempre que sea aplicada a través de parámetros claros.

\section{Referencias}

1. Alexy, R. (2004). El concepto y la validez del Derecho. Editorial Gedisa, Barcelona. España.

2. Alexy, R. (2008). Teoría de los derechos fundamentales. Editorial Centro de Estudios Políticos y Constitucionales.

3. Atienza Rodríguez, M. (1998). A propósito de la argumentación jurídica. Doxa. Cuadernos de Filosofía del Derecho, 2(21), 33-50, https://doi.org/10.14198/DOXA1998.21.2.03.

4. Atienza Rodríguez, M. (2019). Manuel Atienza y la ponderación, en: Cátedra de la cultura jurídica del Centro de Estudios Carbonell de México. https://youtu.be/1mne3a-RSqo.

5. Atienza Rodríguez, M. (2019). Siete tesis sobre el activismo judicial. I Seminario ICON-S Colombia, junio 2019, Recuperado de: https://www.ambitojuridico.com/noticias/analisis/ siete-tesis-sobre-el-activismo-judicial\#comments.

6. Ávila, R (2012). En defensa del neoconstitucionalismo transformador: los debates y los argumentos. Universidad Andina Simón Bolívar, Sede Ecuador. http://hdl.handle. net/10644/2922.

7. Bernal, C. (2003). El neoconstitucionalismo y la normatividad del derecho. Escritos de derecho constitucional y filosofía del derecho. Universidad Externado de Colombia, Bogotá,. www.scielo.org.co/pdf/esju/v11n2/v11n2a14.pdf

8. Bernal, C (2015). La racionalidad de la ponderación. Universidad Nacional Autónoma de México, Instituto de Investigaciones Jurídicas. http://biblio.juridicas.unam.mx/libros/ libro.htm?l=4052.

9. Carbonell Sánchez, M. (2003). Nuevos tiempos. Universidad de la Rioja, 2003, págs. 9-12 DOI: https://es.scribd.com/document/187141143/Carbonell-Miguel-Nuevos-TiemposPara-El-Constitucionalismo

10. Carbonell Sánchez, M. (2010). Neoconstitucionalismo y Derechos fundamentales.

11. Comanducci, P. (2002). Formas de (neo)constitucionalismo: un análisis metateórico. 
Isonomía: Revista de Teoría y Filosofía del Derecho, 16, abril 2002, Alicante, Biblioteca Virtual Miguel de Cervantes, http://www.cervantesvirtual.com/nd/ark:/59851/bmc44605

12. Comanducci, P. (2016). Estudios sobre Constitución y derechos fundamentales. Instituto de Estudios Constitucionales del Estado de Querétaro México.

13. Constitución de la República del Ecuador, (20 de octubre del 2008) Registro Oficial No.449.

14. Corte Constitucional del Ecuador, Sentencia No. 0002-09-SIC-CC del año 2009 dentro del caso 0003-09-IC.

15. Ferrajoli, L. (2011). Constitucionalismo principialista y constitucionalismo garantista. DOXA, Cuadernos de Filosofía del Derecho, 34 (2011). https://rua.ua.es/dspace/ bitstream/10045/32761/1/Doxa_34_02.pdf

16. García Amado, J. (2019). García Amado destroza la ponderación en 20 minutos. Catedra de la cultura jurídica de la Universidad de Girona, , cit., min. 17:00-18:00 https://www. youtube.com/watch?v=bCBcrayDYp8.

17. García Amado, J. (2010). Dónde va el derecho actual. Parte III. https://www.youtube.com/ watch?v=eWPZSkW-00Y

18. García Figueroa, A. (2017). Neoconstitucionalismo y argumentación jurídica. Revista de la facultad de Derecho, Universidad de Castilla-La Mancha, 79. http://www.scielo.org.pe/pdf/ derecho/n79/a01n79.pdf

19. García Figueroa, A. (2017). Praxis: una introducción a la moral, la política y el Derecho. Atelier.

20. Leisner, W. (1997) Der Abwägungsstaat, Duncker \& Humblot, Berlin.

21. Ley Orgánica de Garantías Jurisdiccionales y Control Constitucional del Ecuador, (2009). Registro Oficial Suplemento 52 de 22-oct.-2009. https://municipiobanos.gob.ec/banos/ images/LOTAIP2017/LOGJCC.pdf

22. Luis Vigo, R. (2015). Iusnaturalismo o Neo-constitucionalismo, coincidencias y diferencias". Biblioteca Jurídica Virtual del Instituto de Investigaciones Jurídicas de la UNAM. https:// archivos.juridicas.unam.mx/www/bjv/libros/8/3845/33.pdf

23. Moreso, J. J. (1997). La indeterminación del derecho y la interpretación de la Constitución, Madrid, Centro de Estudios Políticos y Constitucionales, 1997. 
24. Moreso, J.J. (2009). Constitución: un modelo para armar. Marcial Pons, Madrid- BarcelonaBuenos Aires, 2009. https://www.marcialpons.es/media/pdf/100845389.pdf

25. Nino, C.S. (1985). La validez del derecho. Astrea, Barcelona.

26. Prieto Sanchis, L. (2008). El Principio de Proporcionalidad y la Interpretación Constitucional. Ministerio de Justicia. Quito, Ecuador. https://www.sedh.gob.hn/odh/documentos/ derechos-penales/117-el-principio-de-proporcionalidad-y-la-interpretaci\%C3\%B3nconstitucional/file

27. Prieto Sanchís, L. (2011). Ferrajoli y el neoconstitucionalismo principialista. Ensayo de interpretación de algunas divergencias. Universidad de Castilla-La Mancha, DOXA, Cuadernos de Filosofía del Derecho, 34 (2011). https://rua.ua.es/dspace/ bitstream/10045/32773/1/Doxa_34_14.pdf

28. Portocarrero, J. (2017). Ponderación=Balancing. EUNOMIA Revista en Cultura de la legalidad, 12. Madrid.

29. Pozzolo, S. (1998). Neoconstitucionalismo y especificidad de la interpretación constitucional. Doxa 21, núm. II, 1998, pp. 339-353.

30. Pozzolo, S. 2016. Neoconstitucionalismo. Revista en cultura de la Legalidad, 11, 142-151. DOI: http://dx.doi.org/10.20318/eunomia.2016.3284

31. Villaverde, I. (2008). La resolución de conflictos entre derechos fundamentales", en Carbonell, Miguel (ed.), El principio de proporcionalidad y la interpretación constitucional, Quito, Quito, Ecuador, 2008, 1ra. edición: diciembre 2008. https://www.sedh.gob. $\mathrm{hn} / \mathrm{odh} /$ documentos/derechos-penales/117-el-principio-de-proporcionalidad-y-lainterpretaci\%C3\%B3n-constitucional/file

32. Zaidam, S. (2012). Neoconstitucionalismo, teoría y práctica en el Ecuador. Editorial Jurídica Cevallos.

33. Zagrebelsky, G. (2011). El derecho dúctil. Ley, derechos y justicia, 10a. ed., trad. Gascón, Mariana, Trotta, Madrid. 